\title{
Preto não traz confiança: Moacir Barbosa do Nascimento e a Síndrome de Goleiros negros no Brasil
}

\author{
Alexandre Vinicius Nicolino Maciel*
}

DOI: 10.11606/issn.2318-8855.v9i1 p83-101

Resumo: O presente artigo busca debater como o racismo estrutural exerce poder no futebol brasileiro, sobretudo na posição de goleiros. Como ponto-chave desse artigo, há o debate sobre a figura de Moacir Barbosa do Nascimento, goleiro da seleção brasileira na Copa do Mundo de 1950 e principal acusado pelo vice-campeonato do escrete nacional. O artigo percorre a trajetória do futebol desde a sua chegada ao país e a partir de apontamentos estatísticos, expõe como os negros foram sumariamente afastados das posições defensivas e como o gol de Ghiggia, foi utilizado como pretexto para afastar goleiros negros da seleção brasileira e do futebol nacional. A partir do debate bibliográfico aponta a existência de um preconceito exacerbado na sociedade para com goleiros negros, que o "frango" de Barbosa tornou-se uma herança nacional e que o mito da democracia racial não pode ser usado no futebol brasileiro.

Palavras-chave: Barbosa; Goleiros; Seleção Brasileira; Racismo estrutural; Futebol Brasileiro.

\footnotetext{
* Graduando em Licenciatura Plena em História pela Universidade Federal Rural do Rio de Janeiro (UFRRJ). E-mail para contato: alexandrevinicius1996@gmail.com
} 


\section{artigos}

\section{Alexandre Vinicius Nicolino Maciel}

"A maior pena que existe para um crime no Brasil é de trinta anos. Mas desde 1950 eu sou condenado."

Moacir Barbosa do Nascimento em Dossiê 50: os onze jogadores revelam os segredos da maior tragédia do futebol brasileiro de Geneton de Moraes Neto.

Quando se fala em 50, ninguém pensa num colapso geral, numa pane coletiva. Não. O sujeito pensa em Barbosa, o sujeito descarrega em Barbosa a responsabilidade maciça, compacta da derrota. O gol de Ghiggia ficou gravado, na memória nacional, como um frango eterno. O brasileiro já se esqueceu da febre amarela, da vacina obrigatória, da espanhola, do assassinato de Pinheiro Machado. Mas o que ele não esquece, nem a tiro, é o chamado "frango" de Barbosa.

Nelson Rodrigues, Manchete Esportiva, 30/5/1959.

\section{O racismo estrutural na sociedade brasileira}

Para uma boa compreensão do objetivo desse artigo é essencial debater a questão do racismo estrutural para que os apontamentos aqui propostos sejam mais bem compreendidos. No período entre 1550 e 1850, no qual o tráfico escravista foi permitido no país estima-se que mais de quatro milhões de africanos escravizados desembarcaram no Brasil, o Império Português foi a região que mais recebeu escravizados em todo globo, entre os séculos XVI e XIX (IBGE, 2007, p. 82.). Em 520 anos desde a chegada dos portugueses, somente a 132 que a escravidão por cor é proibida, algo próximo de $25 \%$ de toda a história conhecida do país. Esse longo período escravista, aliado à ausência de políticas públicas eficazes, gerou na sociedade brasileira um racismo estrutural que é intrínseco ao seu próprio funcionamento. Essa característica cria mitos em torno de uma suposta democracia racial ou da inexistência de preconceito racial no país, gerando genocídios em longa escala. Um bom referencial para esse debate está no livro de Abdias do Nascimento "O Genocídio do Negro Brasileiro", que 


\section{artigos}

\section{Preto não traz confiança: Moacir Barbosa do Nascimento e a Síndrome de Goleiros \\ negros no Brasil}

enumera inúmeros ambiente nos quais o racismo é camuflado no Brasil em prol da venda de uma imagem diferente do que a realidade exprime. Essa realidade é apontada através da citação a Anani Dzidzienyo em sua obra "A posição do negro na sociedade brasileira" (1971):

A posição do negro brasileiro num Brasil dominado pelos brancos difere daquela dos negros em sociedades similares em qualquer lugar somente na medida em que a ideologia brasileira de não discriminação - não refletindo a realidade e, aliás, camuflando-a - consegue sem tensão o mesmo resultado obtido pelas sociedades abertamente racistas. (NASCIMENTO,1978, p. 136.)

Dentro da lógica impregnada pela elite brasileira desde o século XIX, somente o branqueamento da nação a levaria ao progresso e assim são criados termos que hierarquizam uma sociedade dominada pelo homem branco “(...) os produtos de sangue misto: o mulato, o pardo, o moreno, o pardavasco, o homem-de-côr, o fusco. (NASClMENTO,1978, p. 69.)". Nesse contexto, quanto maior for a elevação em nível social ou mais clara for a cor da pele, mais próximo do branco se está. Esse domínio se dá em diversos meios e formas, nas quais a população negra, maioria absoluta no Brasil em termos populacionais, é feita minoria em representação (IBGE, 2019.). Esse debate será retomado mais à frente quando transportarmos o temática do racismo estrutural para o futebol e apresentarmos alguns relatos que marcam essa característica da sociedade brasileira, no entanto, cabe aqui citar o refrão da música “Identidade" do sambista Jorge Aragão, que bem exemplifica os danos causados pela política do branqueamento: "Se o preto de alma branca pra você/ É o exemplo da dignidade/ Não nos ajuda, só nos faz sofrer/ Nem resgata a nossa identidade." (ARAGÃO, 1992.)

\section{O futebol nasce de elite, mas o povo o faz popular}




\section{artigos}

\section{Alexandre Vinicius Nicolino Maciel}

Feito esse debate inicial é importante pontuar a gênese do futebol e a sua inserção no Brasil. Criado pelos britânicos por volta da metade do século XIX e trazido ao Brasil através de descendentes e/ou migrantes dessa região, ${ }^{1}$ o futebol nasce no país mantendo o caráter elitista que carregava na Europa, os primeiros clubes a praticarem o esporte carregavam o apego o britanismo como marca. De maneira um tanto quanto incoerente, o esporte mais popular do país, afirma-se inicialmente como uma prática que pretendia, através de instituições formadas pela e para a elite branca, aproximar as principais cidades do país da aristocracia europeia:

Clubes como Rio Cricket \& Athletic Association (RJ), Fluminense Football Club (RJ), Club Atlético Paulistano (SP), Associação Atlética do Mackenzie College (SP), Paysandu Cricket Club (RJ), entre outros, mantinham tal tradição elitista e com isso se caracterizavam como símbolo de elegância e sofisticação, imputando-lhe um significado próprio nem sempre condizente com suas reais condições sociais. (SANTOS JUNIOR, 2013, p. 2.)

Os primeiros clubes que tiveram a presença de negros e operários entre seus fundadores e atletas nascem somente a partir da virada para o século XX. O pioneirismo é da AA Ponte Preta de Campinas, fundada em 1900 tinha entre seus fundadores e atletas Miguel do Carmo ${ }^{2}$, apontado como o primeiro atleta negro do futebol brasileiro. Em 1904 nasce dentro de uma fábrica de tecidos no subúrbio carioca, a mesma em que supostamente ocorreu a primeira partida de futebol no país, o Bangu Atlético Clube (inicialmente BANGU ATHLETIC CLUB), iniciando uma nova prática na cidade do Rio de Janeiro com os clubes fabris (SANTOS JUNIOR, 2013, p. 2.). Mesmo sendo de origem

\footnotetext{
${ }^{1}$ A principal tese sobre a gênese do futebol brasileiro defende que seu pai é Charles Miller, paulista, filho de ingleses que foi estudar na terra da Rainha no fim do século XIX e trouxe o esporte para o Brasil, realizando a primeira partida do esporte em 1895. No entanto, uma outra corrente defende que o esporte foi jogado no país pela primeira vez em Bangu, zona Oeste do Rio de Janeiro, por iniciativa do escocês Thomas Donohoe, que teria jogado uma partida de futebol com seus companheiros de trabalhos em 1894.

${ }^{2} \mathrm{O}$ atleta não aparece diretamente no site do clube como fundador do clube na página oficial, sendo lembrado somente no infográfico com datas marcantes da história da instituição. Disponível em: < https://pontepreta.com.br/o-clube/historia >. Acesso em 20 outubro 2019.
} 


\section{artigos}

\section{Preto não traz confiança: Moacir Barbosa do Nascimento e a Síndrome de Goleiros \\ negros no Brasil}

britânica, era formado por operários, o que já demonstra um desapego com as elites. No entanto, o caso mais marcante de inserção de negros em uma equipe de futebol ocorreu no Club de Regatas Vasco da Gama, recém promovido à elite do futebol do Rio de Janeiro em 1923:

[...]chocava o público pelo fato de seu time reunir jogadores - oriundos da Liga Suburbana, diferentemente da liga oficial - negros, analfabetos, suburbanos e vindos das classes populares, algo inimaginável nos grandes clubes, cujos atletas eram brancos, filhos das boas famílias da Zona Sul, boêmios ou estudantes. Num futebol elitizado e oficialmente amador, a atitude vascaína era um ultraje, até porque o clube pagava gratificações aos atletas. Era o chamado 'bicho'." (NOGUEIRA, 2009, p.12-13.)

O caso emblemático do Vasco da Gama, campeão com quatro negros e seis analfabetos no plantel principal (MALAIA SANTOS, 2010, p. 283.), abriu espaço para o debate sobre o profissionalismo no futebol e para que atletas antes proibidos marcassem território dentro do futebol. A presença deles antes desse fato era em um número muito pequeno e sempre alijados, como mostra o ato do presidente Epitácio Pessoa de proibir a participação de jogadores negros na seleção brasileira em 1921 (ALMEIDA, 2017, p.43.). Os poucos que conseguiam se destacar eram "embranquecidos", um exemplo disso é Arthur Friedenreich, primeiro grande craque do futebol brasileiro que era mulato, mas sempre tinha evidenciada sua ascendência alemã (MAGALHÃES, 2010, p. 20.), tal prática reforçava a teoria do branqueamento da nação. "Jogar futebol tornou-se uma forma de subverter uma ordem social existente." (MORAES, 2008, p. 5.)

\section{Os divinos diamantes negros}




\section{artigos}

\section{Alexandre Vinicius Nicolino Maciel}

O primeiro grande resultado do selecionado brasileiro em Copas do Mundo ocorreu em 1938 na França, pela primeira vez as diferenças entre Paulistas, Cariocas e Confederação Brasileira de Desportos não impediu o envio dos melhores jogadores para o campeonato. dois principais jogadores brasileiros eram negros: Domingos da Guia e Leônidas da Silva. Domingos Antônio da Guia, foi o primeiro grande zagueiro do futebol brasileiro, suburbano de Bangu, iniciou clube de seu bairro, era conhecido com El Divino Mestre (O Divino Mestre), devido a forma elegante que jogava, muito diferente dos jogadores de defesa de seu tempo. Leônidas da Silva era outro suburbano, mas de São Cristóvão e apelidado de Diamante Negro, é tido por muitos como o maior jogador do futebol antes de Pelé (CUNHA, 2002, p.144.). O selecionado brasileiro foi eliminado da competição na partida semifinal contra a então campeã mundial Itália. Leônidas havia sofrido uma distensão muscular, que o impediu de entrar em campo (RIBEIRO, 1999, p. 93.), a derrota foi marcada por um lance protagonizado por Domingos e que ficou conhecido como Domingada:

Durante uma paralisação do jogo, o atacante italiano Piola deu um pontapé em Domingos da Guia dentro da área brasileira. Irritado, o zagueiro revidou ali mesmo. A agressão foi vista pelo árbitro suíço Hans Wüthrich, que marcou pênalti . Meazza fez o gol italiano, que já vencia por 1 a 0 . Em desvantagem, o Brasil foi para cima, mas o gol de Romeu não reanimou o time. (ASSAF; RODRIGUES, 2010, p. 35.)

Ao Brasil restou o terceiro lugar na Copa do Mundo e a artilharia de Leônidas com sete gols. A situação de cada atleta ao fim do Mundial expõe bem como a participação brasileira foi interpretada no país. O Diamante Negro, expoente da alegria e do talento brasileiro saiu valorizado, enquanto o Divino Mestre, responsável pela defesa da equipe saiu marcado pelo estigma da insegurança. "De nada valia o talento, se a raça brasileira apequenava-se diante da força e da organização das nações européias. (SARMENTO, 2006, p. 61.)." Se faz importante expor esse mundial, especificamente, pelo fato de que pela primeira vez um selecionado de futebol estava inserido oficial no 


\section{artigos}

\section{Preto não traz confiança: Moacir Barbosa do Nascimento e a Síndrome de Goleiros}

negros no Brasil

contexto de união nacional, por iniciativa do Estado Novo de Getúlio Vargas. Ciente da congregação de massas que o futebol era capaz, o governo estabelece relações que futuramente se convergem em intervenção estatal no esporte, sobretudo no futebol que já era a principal paixão nacional (COSTA, 2013, p. 190.), assim era necessária a propaganda de uma nação na qual todos eram iguais.

\section{A década de 1940 e o surgimento de Moacir Barbosa do Nascimento}

A segunda Guerra Mundial impediu a realização das Copas do mundo de 1942 e 1946, mas no Brasil o futebol se desenvolvia, era a primeira década na qual o profissionalismo era efetivamente realidade no país e mais uma vez o Vasco da Gama surgia como um importante expoente. Na metade da década um selecionado vascaíno que ficou conhecido como "Expresso da Vitória", reunia inúmeros craques, que constantemente figuravam nas convocações da seleção nacional, um dos principias destaques daquela equipe tinha a missão de defender as balizas cruzmaltinas: Moacir Babosa do Nascimento, mais conhecido como Barbosa. Nascido em 27 de março de 1921 em Campinas, iniciou a carreira em 1940 pelo Comercial(SP), passando pelo Ypiranga(SP), até desembarcar no Rio de Janeiro em 1945, atuou ainda por Santa Cruz(PE), Bonsucesso(RJ) e Campo Grande(RJ), onde encerrou a carreira em 1962. A crônica esportiva o chamava de "estilista" pelo seu jeito elegante de jogar futebol e realizar defesas difíceis como algo simples. Teria sido ele o criador da defesa de mão trocada e entre os seus admiradores estava Getúlio Vargas (NOGUEIRA; TAVES, 2011, p. 29.). A glória máxima de Barbosa pelo Vasco da Gama fora o título de Sul-Americano de 1948, no Chile, na partida final contra o River Plate(ARG) fora impecável, inclusive defendendo um pênalti 


\section{artigos}

\section{Alexandre Vinicius Nicolino Maciel}

que garantiu o título para a equipe carioca, fato que fora exaltado pelo crônica carioca, como relata Luiz Mendes: “A atuação dele foi sensacional, muito segura. Quando o Vasco precisou, principalmente no último jogo, ele fez defesas impressionantes. E olha que não era fácil segurar aqueles argentinos. (NOGUEIRA; TAVES, 2011, p. 33.)" Pela Seleção brasileira, atuou entre 1945 e 1953, conquistando a Copa Roca em 1945, a Copa Rio Branco em 1948 e 1950 e o Campeonato Sul-Americano em 1949 (SOTER, 2015, p. 85-99.). A seleção brasileira fora comandada entre 1945 e 1950 por Flávio Costa (SOTER, 2015, p.74.), que desde 1947 era também técnico do Vasco da Gama (NOGUEIRA, 2009, p. 76.). Para a posição de goleiro da seleção nesse período nunca houvera unanimidade, a imprensa paulista defendia a convocação de Oberdan do Palmeiras, no Rio de Janeiro, Castilho do Fluminense era o nome forte, ambos eram brancos, o que reforça a ideia do racismo com defensores, visto por exemplo que o apoiador Zizinho era titular absoluta da equipe. Barbosa só tem a sua titularidade confirmada na seleção somente após o título com o Vasco no Sul-Americano de clubes, o qual foi conquistado sob o comando de Flávio Costa.

\section{6 de julho de 1950: o Maracanazzo e a primeira morte de Barbosa}

Tarde de domingo no Rio de Janeiro, depois de doze anos, o mundo veria novamente uma nação conquistar o mundo através do futebol; depois de vinte anos, dois países sul-americanos chegavam à partida final em busca do título: o Brasil buscava em casa sua primeira estrela, o Uruguai buscava estragar a festa ao conquistar o seu segundo caneco. O clima era de festa, estima-se que mais de 200 mil pessoas estiveram no estádio do Maracanã, para o Brasil bastava o empate, para o Uruguai só a vitória interessava. Todos os gols da partida foram marcados no segundo tempo, a seleção brasileira marcou primeiro, Friaça aos dois minutos, após passe de Ademir. Aos vinte e 


\section{Preto não traz confiança: Moacir Barbosa do Nascimento e a Síndrome de Goleiros}

negros no Brasil

um minutos, Ghiggia partiu em velocidade pelo lado direito de ataque e cruza para Schiaffino empatar a partida. O mesmo Ghiggia, aos 34 minutos partiu livre pelo lado direito e em um chute cruzado, no qual a bola passou entre a trave e Barbosa, o Uruguai virava a partida e ficava com o título mundial (RIBAS, 2013, p. 32.):

Ele deu seis passos, em seis segundos, sem tocar na bola, muito pouca coisa para o futebol mundial, mas os mais longos momentos de sofrimento da história esportiva do Brasil. São passos que até hoje ecoam, como se o alarido e as vozes fantasmagóricas dos 200 mil entusiasmados torcedores que estiveram no Maracanã naquele dia pudessem ser ouvidos, 60 anos depois. O ponta-direita correu incríveis 40 metros sem ser molestado. Mais um passo e ele chutou de peito de pé: $2 \times 1$ para o Uruguai. (MUYLAERT, 2013, p. 13.)

Após a derrota, buscaram-se os culpados. Apontou-se a farra da (des)concentração que presenciou inúmeros discursos políticos naquela manhã antes da partida, como causa da derrota(MUYLAERT, 2013, p.31-33.). Não faltaram narrativas que remetessem ao brasileiro uma inferioridade em relação às outras nações, tal como o complexo de vira-latas cunhado por Nelson Rodrigues ${ }^{3}$, que retomava o debate iniciado após o Mundial de 1938:

(...) surgiu de novo a questão derivado do Estado Novo, a deficiência da 'raça brasileira', causa da sua inferioridade como nação.

Não por coincidência, os principais jogadores responsabilizados pela derrota do Brasil eram todos negros. (MUYLAERT, 2013, p. 45.)

Bigode e Juvenal também foram responsabilizados, no entanto, as principais narrativas culpavam um único indivíduo: Moacir Barbosa do Nascimento. A suposta falha de Barbosa foi um duro golpe na carreira e na vida do goleiro, o antes magistral

\footnotetext{
${ }^{3}$ Expressão criada pelo dramaturgo e cronista Nelson Rodrigues em decorrência do vice-campeonato mundial em 1950, definia que o brasileiro possuía uma fragilidade que o impedia de se impor em embates internacionais, o que causava as seguidas derrotas e o consequentemente depreciação da nação, dessa fragilidade gerava o crescimento de um apreço por tudo que vinha do exterior.
} 


\section{artigos}

\section{Alexandre Vinicius Nicolino Maciel}

passava a ser o frangueiro, o tirano, o vilão, o responsável por fazer o país chorar. Ainda foi convocado à seleção brasileira uma vez mais em 1953 (SOTER, 2015, p.97-98.), ficando de fora do Mundial na Suíça em 1954, segundo o próprio, devido uma contusão (MUYLAERT, 2013, p. 73.). A derrota, no entanto, pode ser considerada a sua primeira morte, o arqueiro carregou até o fim da vida o eterno fardo de ser o culpado pelo vicecampeonato no até então único mundial sediado no Brasil, sua vida (falha) fora abordada em filmes; documentários; reportagens; artigos acadêmicos, publicitários e jornalísticos; livros e capítulos. Por mais que alguns buscassem apresentar um Barbosa além do fatídico 16 de julho, a narrativa sempre apontava para aquele dia, aquele jogo, aquele lance, aquele gol. "Sem dúvida, o modo como se costuma reiterar, na imprensa e em publicações sobre futebol, a suposta 'culpa' de Barbosa passa pela elaboração discursiva de um verdadeiro drama" (CORNELSEN, 2013, p. 9.). Sob a perspectiva de Pollak (POLLAK, 1992, p. 204.), o gol de Ghiggia, pelo tanto que fora comentado e reproduzido, tornou-se um elemento da memória coletiva, o mesmo se tornou uma herança deixada ao povo brasileiro:

(...) de outra vez, no Rio, eu tomava um limãozinho num bar de um amigo, quando entra uma senhora com um menino e fala 'olha, meu filho, vem cá, está vendo esse homem aí, é ele que fez todo o Brasil chorar', o garoto ficou olhando fixo para a minha cara, com um ar de condenação e consternação, então eu não aguentei e respondi 'escuta aqui, minha senhora, se eu fosse seu filho queria ver se a senhora teria coragem de dizer isso, é porque não sou seu filho, senão a senhora também estaria sofrendo na pele', ela também não tinha nascido na época da Copa, então já eram duas gerações que não estavam neste mundo no dia daquela final, me acusando. (MUYLAERT, 2013, p. 68-69.)

Após a aposentadoria dos gramados, Barbosa trabalhou durante vinte e nove anos no mesmo endereço em que fora sepultado em 1950, as traves defendidas por ele na final da Copa do Mundo, se tornaram lenha para um churrasco (MUYLAERT, 2013, p. 64-65). Moacir Barbosa do Nascimento morreu definitivamente em 7 de abril de 2000, aos 79 anos em Praia Grande (NOGUEIRA; TAVES, 2011, p. 39.). 


\section{artigos}

\section{Preto não traz confiança: Moacir Barbosa do Nascimento e a Síndrome de Goleiros \\ negros no Brasil}

\section{O não aos goleiros negros}

Após Barbosa, o primeiro goleiro negro a ser titular da seleção em uma Copa do Mundo, somente em 1966 um goleiro não-branco disputou uma partida pela seleção brasileira em Copas, Haílton Correia de Arruda, o Manga atuou apenas na última partida da fase de grupos, falhando em dois lances cruciais que culminaram em gols da seleção portuguesa, que venceu a partida por 3×1. Depois da derrota Manga só atuou mais uma vez pela seleção (STEIN, 2017.), apesar da malograda partida, o arqueiro teve uma carreira espetacular por clubes e no Brasil, o dia do goleiro é datado em sua homenagem (RODRIGUES, 2004, p. 57.). Demorou quarenta anos para novamente a camisa 1 da seleção brasileira em uma copa do Mundo não ser vestida por um branco, 56 anos para um negro: Nelson de Jesus Silva, o Dida, foi o escolhido. Presença constante na seleção brasileira desde a metade da década de 1990, foi titular e campeão da Copa América em 1999 e da Copa da Confederações em 1997 e 2005. Em mundiais esteve presente no vice-campeonato na França em 1998 e no pentacampeonato na Coréia do Sul e do Japão em 2002, mas sempre como reserva. Apesar de ser um dos principais goleiros do mundo, Dida nunca foi unânime na seleção brasileira, sempre teve a sombra da preferência por goleiros brancos, pouco antes do mundial a sua titularidade ainda era questionada, o humorista Chico Anysio em texto para o jornal Lance, usou Barbosa como exemplo para a sua desconfiança em Dida: “Não tenho confiança em goleiro negro. O último foi Barbosa, de triste memória na seleção. (BLOG OS FERAS, 2012.)". O goleiro fora mais um que sofrera o processo branqueamento para ter o seu potencial valorizado. O ex-atacante Edilson, que atuou com Dida no Corinthians e na 


\section{artigos}

\section{Alexandre Vinicius Nicolino Maciel}

Seleção Brasileira, afirmou o seguinte: “Deixa chegar a hora certa. O Dida não era negão. É pardozinho. (...) Tem coisas no futebol que vocês não jogaram, vocês não entendem. Goleiro negão é igual... Rapaz... Tá bom, depois vocês vão dizer... "4" A fala de Edilson é ainda mais alarmante pelo fato de o atleta também ser negro, mas exemplifica a prática acima descrita da cultura do branqueamento que é impregnada na estrutura racista da sociedade. Dida, ao alcançar uma posição elevada na sua carreira é automaticamente desprendido de suas raízes e transportado ao patamar de pardo.

Após Dida, dezesseis goleiros entraram em campo pela seleção, somente três não eram brancos ${ }^{5}$, nenhum deles em Copas do Mundo e somente um em competições oficiais, Jefferson na Copa América de 2015. O saldo total dessa conta é de 106 goleiros que atuaram, sendo que 92 brancos e 14 negros (GUILHERME, 2019). Desde 2016 no comando da seleção brasileira, o técnico Tite nunca convocou um negro para a seleção principal e apenas um único pardo, Alex Muralha. Essa desconfiança não se sustenta somente na seleção brasileira principal, em 2018, logo após se aposentar dos gramados, Jefferson goleiro com passagens por Botafogo e seleção, confidenciou que teve sua convocação para o mundial sub-20 em 2003 barrada por ser negro ${ }^{6}$.

Essa barreira não se resume à seleção brasileira, em 2014, o goleiro Aranha então no Santos foi vítima de racismo por parte da torcida do Grêmio no confronto entre as duas equipes pela Copa do Brasil (MANERA; CARVALHO, 2015, p. 8.). Em 2015, a própria torcida santista insultou o goleiro através das redes sociais, após o atleta acionar

\footnotetext{
${ }^{4} \mathrm{O}$ ex-atacante participava de um programa no canal Fox Sports e comentava a atuação do goleiro do Palmeiras Jaílson que é negro, o vídeo da fala pode ser visualizado em: https://www.youtube.com/watch?v=t5UpdmuzVlk\&feature=share . Acesso em 07 março 2020. A transcrição da fala foi feita pelo autor.

${ }^{5}$ Hélton, Gomes e Jefferson são os não-brancos que foram a campo pela seleção depois de Dida.

${ }^{6} \mathrm{~A}$ fala foi feita no programa Resenha ESPN e pode ser visualizada em https://www.youtube.com/watch?v=2U4wXNRQjQ4\&feature=share . Acesso em 8 março 2020.
} 


\section{artigos}

\section{Preto não traz confiança: Moacir Barbosa do Nascimento e a Síndrome de Goleiros}

negros no Brasil

o clube na justiça (MANERA, 2016, p. 29.). Já em 2020, o goleiro Alexander do Vasco foi alvo de injúrias raciais vindas da torcida do Oriente Petrolero da Bolívia (O GLOBO, 2020.).

O Observatório da Discriminação Racial no Futebol, iniciativa da Universidade Federal do Rio Grande do Sul que desenvolve relatórios anuais desde 2014 apresenta um diagnóstico mais amplo sobre o debate. No primeiro ano, dos vinte casos de racismo ocorridos no Brasil listados, seis foram contra goleiros (MANERA; CARVALHO, 2015, p. 7-9.). Em 2015, em trinta e cinco, dois foram contra goleiros (MANERA, 2016, p. 29-34.). No ano de 2016, um único caso em 25 registrados, tal ocorrência ainda continha caráter machista e fora proferido contra a goleira Bárbara da Seleção Brasileira (MANERA, 2017, p. 13-21.). Quarenta e três foram os casos em 2017, nenhum contra goleiros (OBSERVATÓRIO DA DISCRIMINAÇÃO RACIAL NO FUTEBOL, 2018, p. 15-29). No último relatório, do ano de 2018 marcou um recorde infeliz no número de casos, quarenta e quatro, desses somente um caso fora contra goleiros, a já citada fala de Edilson sobre o goleiro Jailson e goleiros negros (OBSERVATÓRIO DA DISCRIMINAÇÃO RACIAL NO FUTEBOL, 2019, p. 26-38.). Poderíamos ainda listar inúmeros casos ou até mesmo explicitar cada um dos citados acima, tanto no Brasil, quanto no exterior, porém o objetivo do artigo é analisar os goleiros negros no futebol brasileiro e apresentamos alguns casos que dão o tom do debate. "As feridas da discriminação racial se exibem ao mais superficial olhar sobre a realidade social do país (NASCIMENTO,1978, p. 82.)"

\section{Considerações Finais}




\section{artigos}

\section{Alexandre Vinicius Nicolino Maciel}

A ausência histórica de goleiros negros na seleção brasileira reflete não só uma condição traumática pós-Copa de 1950, mas um reflexo do racismo estrutural que se impõem no Brasil: “O racismo é uma decorrência da própria estrutura social, ou seja, do modo 'normal' com que se constituem as relações políticas, econômicas, jurídicas e até familiares, não sendo uma patologia social e nem um desarranjo institucional. O racismo é estrutural (ALMEIDA, 2018, p.38.)". Reflete-se no campo uma estrutura que é própria da sociedade brasileira, dos onze goleiros brasileiros que foram campeões do mundo, somente um era negro, esses dados além de alarmantes refletem a prática de não pôr negros em posições nas quais a segurança e confiança são tidas como altamente necessárias, algo que pode ser observado por qualquer indivíduo ao seu redor com uma simples análise. No futebol especificamente, além dos goleiros, pode-se apontar também a quantidade de pretos e pardos como técnicos e dirigentes esportivos.

Para afastar o debate do evidente racismo no futebol, que para muitos é um ambiente onde a democracia racial impera, busca-se justificar essa ausência na questão do mérito, o próprio Barbosa trata a ausência de goleiros negros na seleção como bobagem (MUYLAERT, 2013, p. 76.). Não cabe aqui condenar o ex-goleiro, mas a sua afirmação aponta a impregnação do racismo na sociedade, na qual o próprio negro, se entende como culpado e não como vítima. “No Brasil, a negação do racismo e a ideologia da democracia racial sustentam-se pelo discurso da meritocracia. Se não há racismo, a culpa pela própria condição é das pessoas negras que, eventualmente, não fizeram tudo que estava a seu alcance. (ALMEIDA, 2018, p.63.)" A supracitada democracia racial se sustenta no futebol sobretudo nos êxitos de Pelé, Garrincha e Didi no primeiro Mundial conquistado pelo Brasil em 1958, na Suécia. Entretanto, pouco se fala da desconfiança incorrida sobre os mesmos no início do mundial, que causou a quase 


\section{artigos}

\section{Preto não traz confiança: Moacir Barbosa do Nascimento e a Síndrome de Goleiros}

negros no Brasil

total ausência de negros na partida de estreia contra a Áustria, Didi era o único em campo. A privação se justificava num suposto relatório científico de 1956, que apontava as causas das derrotas brasileiras em Copas do Mundo e em competições no exterior como fruto da inferioridade psíquica de negros. Não por acaso, pela primeira vez um psicólogo fazia parte da comissão técnica (OBSERVATÓRIO, 2015.). Além disso, os não raros casos de racismo no futebol brasileiro confirmam a inexistência de democracia racial nesse ambiente, quanto mais no país em sua totalidade.

Esse breve trabalho busca apontar que o racismo com atletas que atuam na faixa defensiva já era uma recorrente no futebol brasileiro desde o início, o "frango" de Barbosa em 1950 é apenas pretexto para uma narrativa que supõe a incompetência de negros enquanto arqueiros, algo que já era feito com zagueiros após a falha de Domingos da Guia em 1958. O fato se torna mais marcante com goleiros pelo fato da própria posição já ser estigmatizada no futebol e pelo peso da partida contra o Uruguai. Assim ao perpassar a vida de Moacir Barbosa do Nascimento, buscamos apontar os males que o gol de Alcides Ghiggia Ihe causara e que a memória daquele fatídico momento se impregnou na sociedade brasileira tal como uma herança. Aqui são apontados os casos de mais fácil acesso na mídia, que mesmo assim são pouco conhecidos da grande parte da população. Pretendemos com esse trabalho ser um pontapé, para que tal temática seja dissecada em outras perspectivas e recortes, em busca da conscientização e consequente erradicação do racismo não só no futebol, mas em toda sociedade. 


\section{artigos}

\section{Alexandre Vinicius Nicolino Maciel}

\section{REFERÊNCIAS BIBLIOGRÁFICAS}

ALMEIDA, Silvio Luiz de. O que é racismo estrutural?. 1. ed. Belo Horizonte: Letramento, 2018.

ALMEIDA, Rodrigo Accioli. Canários e condores: as relações políticas durante a Ditadura Militar (1964-1985) e a configuração territorial do futebol no Brasil. 2017. 93f. Monografia (Bacharelado em Geografia) - Departamento de Geografia, Faculdade de Letras e Ciências Humanas, Universidade de São Paulo, São Paulo, 2017.

ARAGÃO, Jorge. Identidade. Chorando Estrelas. Rio de Janeiro: Som Livre, 1992. Disponível em: < https://www.youtube.com/watch?v=TykWraXydpY\&feature=share $>$. Acesso em 14 maio 2020.

ASSAF, Roberto; RODRIGUES, Jefferson. Todas as Copas: 1930 - 2006. 3 ed. Rio de Janeiro: Areté Editorial, 2010.

BLOG OS FERAS. Chico Anysio no futebol: comentarista, caricatura Coalhada e polêmica do goleiro negro. UOL Esporte. 23 março 2012. Disponível em: https://uolesportevetv.blogosfera.uol.com.br/2012/03/23/chico-anysio-no-futebol-comentarista-caricatura-coalhada-e-polemica-do-goleiro-negro/?mobile >. Acesso em: 07 março 2020.

CORNELSEN, Elcio Loureiro. A memória do trauma de 1950 no testemunho do goleiro Barbosa. Esporte e Sociedade, v. 21, p. 1-15, 2013.

COSTA, Maurício da Silva Drumond. Estado Novo e esporte: uma análise comparada dos usos políticos do esporte nos regimes de Getúlio Vargas e Oliveira Salazar (1930-1945). 2013. 222f. Tese (Doutorado em História Comparada) - Universidade Federal do Rio de Janeiro, Instituto de Filosofia e Ciências Sociais. Rio de Janeiro, 2013.

CUNHA, Loris Baena. O Brasil nas Copas do Mundo. Rio de Janeiro: Maanaim Editora, 2002.

GUILHERME, Paulo. Goleiros Negros [mensagem pessoal]. Mensagem recebida por alexandrevinicius1996@gmail.com em 22 out. 2019.

IBGE. Pretos ou pardos estão mais escolarizados, mas desigualdade em relação aos brancos permanece. Agência IBGE. 13/11/2019. Disponível em: < 


\section{artigos}

\section{Preto não traz confiança: Moacir Barbosa do Nascimento e a Síndrome de Goleiros}

negros no Brasil

https://agenciadenoticias.ibge.gov.br/agencia-sala-de-imprensa/2013-agencia-de-noticias/releases/25989-pretos-ou-pardos-estao-mais-escolarizados-mas-desigualdadeem-relacao-aos-brancos-permanece >. Acesso em 13 maio 2020.

IBGE. Brasil: 500 anos de povoamento. Rio de Janeiro: IBGE, 2007.

MAGALHÃES, Lívia Gonçalves. . Histórias do futebol. São Paulo: Arquivo Público do Estado, 2010.

MALAIA SANTOS, João Manuel Casquinha. Revolução Vascaína (1915 - 1934): a profissionalização do futebol e a inserção socioeconômica de negros e portugueses no Rio de Janeiro do início do século XX. 2010. 489f. Tese (Doutorado em História Econômica) Faculdade de Filosofia, Letras e Ciências Humanas, Universidade de São Paulo, São Paulo, 2010.

MANERA, Débora Macedo da Silveira; et al. Relatório anual da discriminação racial no futebol 2016. Porto Alegre: UFRGS, 2017.

MANERA, Débora Macedo da Silveira; et al. Relatório anual da discriminação racial no futebol 2015. Porto Alegre: Observatório da Discriminação Racial do Esporte, Escola de Educação Física, Fisioterapia e Dança/UFRGS, 2016.

MANERA, Débora Macedo da Silveira; CARVALHO, Marcelo Medeiros. Relatório anual da discriminação racial no futebol 2014. Porto Alegre: Observatório da Discriminação Racial do Esporte, Escola de Educação Física, Fisioterapia e Dança/UFRGS, 2015.

MORAES, Hugo da Silva. O Jogo dos Sentidos: O Escrete Vascaíno e a Conquista do Campeonato Carioca de 1923. In: Encontro de História Anpuh-Rio: Identidades, 2008, Seropédica. Anpuh-Rio: Identidades, 2008.

MUYLAERT, Roberto. Barbosa: um gol que silencia o Brasil. 2ed. São Paulo: Bússola, 2013.

NOGUEIRA, Claudio; TAVES, Rodrigo. Os dez mais do Vasco da Gama. Rio de Janeiro: Maquinária, 2011. 
NOGUEIRA, Claudio (org.). O time do meu coração - Club de Regatas Vasco da Gama. Belo Horizonte: Editora Leitura, 2009.

OBSERVATÓRIO DA DISCRIMINAÇÃO RACIAL NO FUTEBOL. Relatório anual da discriminação racial no futebol 2018. Porto Alegre : Museu da UFRGS, 2019.

OBSERVATÓRIO DA DISCRIMINAÇÃO RACIAL NO FUTEBOL. Relatório anual da discriminação racial no futebol 2017. Porto Alegre : Museu da UFRGS, 2018.

OBSERVATÓRIO. E os psicólogos não queriam os negros.... Observatório da Discriminação Racial no Futebol. Porto Alegre, 20 outubro 2015. Disponível em: < https://observatorioracialfutebol.com.br/e-os-psicologos-nao-queriam-os-negros/ >. Acesso em $18 \mathrm{fe}$ vereiro 2020.

O GLOBO, Goleiro do Vasco, Alexander é chamado de macaco na Bolívia; clube lamenta episódio de racismo. O Globo. Rio de Janeiro, 20 fevereiro 2020. Disponível em: < https://oglobo.globo.com/esportes/goleiro-do-vasco-alexander-chamado-de-macacona-bolivia-clube-lamenta-episodio-de-racismo-24259831 >. Acesso em 14 maio 2020.

POLLAK, Michael. Memória e Identidade social. Estudos Históricos, Rio de Janeiro, v. 5, n. 10, p. 200-212, 1992.

RIBAS, Lycio Vellozo. O mundo das Copas. 1 ed. São Paulo: Academia do Livro, 2014. RIBEIRO, André. O Diamante negro: biografia de Leônidas da Silva. 2 ed. Rio de Janeiro: Gryphus, 1999.

RODRIGUES, Rodolfo. O Livro das datas do futebol. 1 ed. São Paulo: Panda Books, 2004. SANTOS JUNIOR, Nei Jorge dos. Quando a fábrica cria o clube: o processo de organização do Bangu Athletic Club (1910). Recorde: Revista de História do Esporte, Rio de Janeiro, v. 6,n.1, jan.-jun. 2013.

SARMENTO, Carlos Eduardo. A regra do jogo: uma história institucional da CBF. Rio de Janeiro: CPDOC, 2006.

SOTER, Ivan. Enciclopédia da Seleção: 100 anos de seleção brasileira de futebol. Rio de Janeiro: Folha Seca, 2015. 


\section{artigos}

Preto não traz confiança: Moacir Barbosa do Nascimento e a Síndrome de Goleiros negros no Brasil

STEIN, Leandro. Os 80 anos de Manga, o gigante de três esquadrões, o responsável pelo “Dia do goleiro'. Trivela. Disponível em: < https://trivela.com.br/os-80-anos-de-mangao-gigante-de-tres-esquadroes-o-responsavel-pelo-dia-do-goleiro/ >. Acesso em: 07 março 2020. 